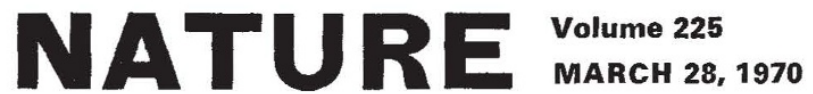

\section{Senator Mansfield, His Mark}

ThE irony of the scandal which has arisen in the United States (see page 1185) about the continued financing of basic research originally supported by mission oriented agencies is that Senator Mansfield, to whom belongs section 203 of the defence appropriations bill for 1970 , is essentially a liberal man. His quarrel last December was with the Pentagon, not with American science. In other circumstances, it is easy to see how he could have been the champion of academic research, for is it not one of the ways in which the United States has become not merely economically overwhelming but intellectually important? The first conclusion, then, is that it is not the senator who should be reformed, but the system.

What has now happened in the United States is that the Congress has imposed a test of relevance on the scientific research which may be supported by the mission oriented agencies, and there is a danger that the result may be such a rapid shift of emphasis that many parts of science will be seriously harmed. Although the budgets of the two agencies-the National Science Foundation and the National Institutes of Health-which are chiefly responsible for detached research have been increased, the increase is not enough to keep pace with the inflation of two years and certainly not enough to make sure that the research projects being abandoned by the mission agencies will be continued. And it is always possible that Congress will cut back the funds asked for by the National Science Foundation and the National Institutes of Healththe foundation has usually been unlucky.

The first thing to be said is that, in principle, it is entirely proper that there should be a shift from the American tradition that most basic research is a pensioner of mission oriented activity to one in which it is supported for its own sake. For several years it has been assumed that the National Science Foundation should be a haven of last resort, able to hold the ring between the richer agencies to which the support of academic research is a peripheral activity, and even now the foundation accounts for only 14 per cent of government support for academic science. The boot should properly be on the other foot, and the National Science Foundation should be able to provide for the hard core of academic science, not just the frosting on the cake. The demand by the congressional panel (see page 1186) that the right of mission agencies to support academic research should be regarded as a permanency is therefore mistaken-indeed, it is already intolerable that the National Aeronautics and Space Administration should be the chief supporter of academic research in astronomy simply because congressmen do not know the difference between that and space research. In the same way, it is shabby that in the coming year the US Atomic Energy Commission should have had to withdraw support from the accelerator operated jointly by Princeton and the University of Pennsylvania so as to accommodate the new $200 \mathrm{GeV}$ accelerator within a more or less fixed budget.

This is why the most serious failure of the past few years has been the indifference of the Administration to the need for a greater concentration of support for basic research on agencies which are explicitly concerned with that. There have been suggestions that the National Science Foundation should grow, in the course of time, but neither the Administration as a whole nor the Office of Science and Technology has ever given a strong lead. What proportion should be the target? To be sure, there are difficulties. Many of the committees of Congress, for example, would resist the notion that exciting areas of research should become the property, so to speak, of others. It is also likely that the mission oriented agencies would resist a concentration of responsibility for basic research elsewhere, but the national interest that agencies such as the Department of Defense should have strong links with basic science can be safeguarded in other ways. And what, in any case, are administrations for if not to work out a rational balance between the necessarily conflicting interests of different agencies? Is Congress really able to prevent the Administration making up its own mind about the headings under which it applies for public money? One sign of the Administration's weakness on this issue is that it has so far conspicuously shied away from comment on the two reports produced by the National Science Board, the first of which, a year ago, argued the case for an explicit federal commitment to graduate education, and the second, only a few weeks ago, asked for just the concentration of resources in the National Science Foundation now shown to be urgently necessary.

But should the concentration of resources go as far as a government department, with a Secretary for Science and Technology able to rub shoulders (and break lances) with the big departments? This has often been advocated as a solution for problems like those of the present. The chances are that it would go too far. In strictly administrative terms, the immediate need is modest. Some way has to be found for providing continuity and a good sense of priorities in the spending of $\$ 1,600$ million a year directly in universities and a comparable sum on the support of laboratories such as the great accelerator centres and the observatories which are widely used by academics. A suitably strengthened National Science Foundation should be able to manage well enough. For the time being it will be quite sufficient if the machinery which exists can be put to better use. 